\title{
Intrathecal Th17- and B cell-associated cytokine and chemokine responses in relation to clinical outcome in Lyme neuroborreliosis: a large retrospective study
}

${\text { Paula Gyllemark }{ }^{1 *} \text {, Pia Forsberg }}^{2}$, Jan Ernerudh ${ }^{3}$ and Anna J. Henningsson ${ }^{4}$

\begin{abstract}
Background: B cell immunity, including the chemokine CXCL13, has an established role in Lyme neuroborreliosis, and also, T helper (Th) 17 immunity, including IL-17A, has recently been implicated.

Methods: We analysed a set of cytokines and chemokines associated with B cell and Th17 immunity in cerebrospinal fluid and serum from clinically well-characterized patients with definite Lyme neuroborreliosis (group 1, $n=49$ ), defined by both cerebrospinal fluid pleocytosis and Borrelia-specific antibodies in cerebrospinal fluid and from two groups with possible Lyme neuroborreliosis, showing either pleocytosis (group $2, n=14$ ) or Borrelia-specific antibodies in cerebrospinal fluid (group 3, $n=14$ ). A non-Lyme neuroborreliosis reference group consisted of 88 patients lacking pleocytosis and Borrelia-specific antibodies in serum and cerebrospinal fluid.

Results: Cerebrospinal fluid levels of B cell-associated markers (CXCL13, APRIL and BAFF) were significantly elevated in groups 1, 2 and 3 compared with the reference group, except for BAFF, which was not elevated in group 3. Regarding Th17-associated markers (IL-17A, CXCL1 and CCL20), CCL20 in cerebrospinal fluid was significantly elevated in groups 1, 2 and 3 compared with the reference group, while IL-17A and CXCL1 were elevated in group 1. Patients with time of recovery $<3$ months had lower cerebrospinal fluid levels of IL-17A, APRIL and BAFF compared to patients with recovery $>3$ months.
\end{abstract}

Conclusions: By using a set of markers in addition to CXCL13 and IL-17A, we confirm that B cell- and Th17-associated immune responses are involved in Lyme neuroborreliosis pathogenesis with different patterns in subgroups. Furthermore, IL-17A, APRIL and BAFF may be associated with time to recovery after treatment.

Keywords: Lyme neuroborreliosis, Cerebrospinal fluid, Cytokines, Chemokines, APRIL, BAFF, CCL20, CXCL 1, CXCL13, IL-17A

\section{Background}

Lyme neuroborreliosis (LNB) is the dominating disseminated form of Lyme borreliosis in Sweden [1] as well as in Europe [2]. The pathogenesis of LNB involves a complex immune response with an initial innate response elicited by Borrelia burgdorferi (B.b.) interacting with

\footnotetext{
* Correspondence: paula.gyllemark@rjl.se

${ }^{1}$ Department of Infectious Diseases, Region Jönköping County, SE-551 85 Jönköping, Sweden

Full list of author information is available at the end of the article
}

recognition receptors such as Toll-like receptor 2, subsequently resulting in activation and recruitment of $\mathrm{B}$ and $\mathrm{T}$ cells to the central nervous system (CNS). The chemokine C-X-C motif ligand (CXCL) 13 is a key molecule in $\mathrm{B}$ cell recruitment to the CNS [3], and several studies have shown high concentrations of CXCL13 in the cerebrospinal fluid (CSF) in both children and adults with LNB [4-6]. CXCL13 is postulated to be a diagnostic marker in acute LNB since it may be elevated in CSF before intrathecally produced B.b.-specific antibodies 
can be detected; however, different cutoff levels have been discussed, e.g. 142 and $250 \mathrm{pg} / \mathrm{mL}$, respectively [4-8]. The cytokines a proliferation-inducing ligand (APRIL) and B cell activating factor (BAFF) are important in B cell development and survival [9], and raised CSF levels have been detected in other neuroinflammatory conditions $[10,11]$. Although increased BAFF levels in CSF have been reported in LNB [12], the relative contribution of B cell-associated factors such as CXCL13, APRIL and BAFF in LNB inflammation and clinical outcome is mainly unknown.

Recent studies have indicated involvement of $\mathrm{T}$ helper (Th)17 cells in the intrathecal immune response in patients with LNB [13-15]. IL-17A, a cytokine produced by Th17 cells, is a potent activator of neutrophils in defeating extracellular microbes, but its wider role in the pathogenesis and clinical outcome of LNB is unclear $[13,16,17]$. CXCL1 (previously known as growth regulated oncogene- $\alpha, \mathrm{GRO}-\alpha)$, a neutrophil recruiting chemokine, and CCL20 (macrophage inflammatory protein-3 $\alpha$, MIP-3 $\alpha$ ) a Th17 recruiting chemokine, are both induced by Th17 cells [17]. While elevated IL-17A levels in CSF have been reported in LNB [13-15], information on its potential association with clinical outcome is still lacking, and it is not known if chemokines downstream of Th17 are increased in LNB.

A basic understanding of the molecules involved in the pathogenesis is a prerequisite for the identification of prognostic biomarkers and in the long run for finding potential therapeutic targets. The aims of this study were to evaluate the putative involvement of Th17- and B cell-associated immune response and to assess associations with disease course in LNB by analysing IL-17A and its downstream chemokines CCL20 and CXCL1, as well as B cell-associated factors APRIL, BAFF and CXCL13.

\section{Methods \\ Patients}

We included retrospectively 165 patients in Jönköping County, Sweden, who had been investigated by lumbar puncture (LP) and blood sampling during 2007-2009 to verify or exclude suspected LNB. Medical records were scrutinized, and the patients were divided into four groups based on the CSF findings (see Tables 1, 2 and 3 for demographic and clinical characteristics) and in accordance with the European Federation of Neurological Societies (EFNS) guidelines [18]. Patients in group 1 (definite LNB, $n=49$ ) had both CSF pleocytosis and Borrelia-specific antibodies in CSF. Group 2 (possible LNB pleocytosis, $n=14$ ) had symptoms strongly suggestive of LNB, short duration of symptoms and CSF pleocytosis but not (yet) Borrelia-specific antibodies in CSF. Group 3 (possible LNB Ab ${ }^{+}, n=14$ ) had Borreliaspecific antibodies in CSF, but no pleocytosis and symptoms were less suggestive of LNB. As a non-LNB reference group, we selected 88 gender- and agematched patients from the same cohort investigated for suspected LNB 2007-2009, in whom LNB was excluded based on no Borrelia-specific serum or CSF antibodies, no CSF pleocytosis and normal CSF-albumin. The reference group consisted of patients where the LP was part of a neurological investigation and in whom no neurological diagnosis was verified $(n=56)$ or they later received other neurological diagnoses such as Bell's palsy $(n=18)$ or Alzheimer's disease, Parkinson's disease and stroke $(n=14)$.

\section{Serum and CSF}

Serum and CSF samples were drawn prior to antibiotic treatment and stored at $-20{ }^{\circ} \mathrm{C}$.

All tests were performed at the clinical laboratory of microbiology in Jönköping. Borrelia-specific antibodies in serum and CSF were analysed using Lyme Borreliosis ELISA kit 2nd generation (Dako Cytomation, A/S, Glostrup, Denmark) between 2007 and 2008. Intrathecal antibody index (AI) was calculated using total IgG as a reference molecule [19] according to the formula: ((Borrelia-specific IgG in CSF (OD)/Borrelia-specific IgG in serum $(\mathrm{OD})) /($ total $\mathrm{IgG}$ in CSF $(\mathrm{mg} / \mathrm{L}) /$ total IgG in serum $(\mathrm{g} / \mathrm{L}))[20]$. A Borrelia-specific AI $>2$ was indicative of intrathecal anti-Borrelia antibody production. From 2009, the laboratory used the IDEIA (Lyme Neuroborreliosis kit, (Dako Cytomation)). Both antibody assays use purified, native $B$. afzelii strain DK1 flagellum as test antigen, and results were interpreted according to the manufacturer's instructions.

\section{Cytokine and chemokine analyses}

APRIL, BAFF and CXCL13 were analysed by ELISA (Invitrogen Immunoassay Kit, KHC3051, Life Technologies, USA, and Quantikine, DBLYSOB and DCX130, (R\&D) Systems, Inc., USA, respectively). IL-17A, CXCL1 and CCL20 were analysed by Luminex multiple bead technology (Milliplex Human Cytokine/Chemokine Kit, Millipore Corporation, Germany). All analyses were conducted according to the manufacturers' instructions. The lowest detection limits were as follows: APRIL: $0.02 \mathrm{pg} / \mathrm{mL}$, BAFF: $0.05 \mathrm{pg} / \mathrm{mL}$ in serum, $0.04 \mathrm{pg} / \mathrm{mL}$ in CSF; CXCL13: $0.04 \mathrm{pg} / \mathrm{mL}$ in serum, $0.03 \mathrm{pg} / \mathrm{mL}$ in CSF; IL-17A: $0.38 \mathrm{pg} / \mathrm{mL}$ in serum, $0.06 \mathrm{pg} / \mathrm{mL}$ in CSF; CXCL1: $3.2 \mathrm{pg} / \mathrm{mL}$ in serum, $0.14 \mathrm{pg} / \mathrm{mL}$ in CSF; CCL20: $0.29 \mathrm{pg} / \mathrm{mL}$ in serum, $0.84 \mathrm{pg} / \mathrm{mL}$ in CSF. Values under the detection limit were given half the value of the lowest point of the standard curve.

\section{Data handling and statistical analyses}

For statistical analyses, SPSS version 20 was used. Intergroup comparisons were performed by using the non- 
Table 1 Characteristics of the four study groups

\begin{tabular}{|c|c|c|c|c|}
\hline & $\begin{array}{l}\text { Group } 1 \\
\text { Definite LNB } \\
n=49\end{array}$ & $\begin{array}{l}\text { Group } 2 \\
\text { Possible LNB pleocytosis } \\
n=14\end{array}$ & $\begin{array}{l}\text { Group } 3 \\
\text { Possible LNB Ab } \\
n=14\end{array}$ & $\begin{array}{l}\text { Group } 4 \\
\text { Non-LNB patients } \\
n=88\end{array}$ \\
\hline Borrelia-specific Al or Borrelia-specific antibodies in CSF & + & - & + & - \\
\hline CSF pleocytosis & + & + & - & - \\
\hline Borrelia-specific lgG/lgM antibodies detected in serum, $n(\%)$ & $43(88)$ & $11(79)$ & $8(57)$ & $0(0)$ \\
\hline CSF-albumin/S-albumin median (range) & $16(3.4-69)^{* * *}$ & $5.8(2.7-45)^{*}$ & $5.7(2.4-17)$ & $4.0(1.5-9.5)$ \\
\hline IgG-index median (range) & $0.7(0.0-2.6)^{* * *}$ & $0.6(0.4-0.8)^{* * *}$ & $0.5(0.4-0.6)$ & $0.5(0.0-0.6)$ \\
\hline Men $n(\%)$ & $29(59)$ & $9(64)$ & $8(57)$ & $39(44)$ \\
\hline Women $n(\%)$ & $20(41)$ & $5(36)$ & $6(43)$ & $49(56)$ \\
\hline Median age years (range) & $32(4-72)$ & $8.5(3-39)^{* *}$ & $62(32-82)^{*}$ & $23(1-83)$ \\
\hline Median duration symptoms before LP weeks (range) & $2.0(0.1-104)$ & $0.5(0.1-3.0)^{*}$ & $2.0(0.1-156)$ & $4.0(0.1-520)$ \\
\hline Head/neck pain $n(\%)$ & $32(65)$ & $6(43)$ & $8(57)$ & $27(31)$ \\
\hline Cranial nerve palsy $n(\%)$ & $22(45)$ & $9(64)$ & $0(0)$ & $20(23)$ \\
\hline Radiculitis $n(\%)$ & $20(41)$ & $2(14)$ & $1(7)$ & $0(0)$ \\
\hline $\begin{array}{l}\text { Patients with duration of symptoms after treatment } \\
\text { under } 3 \text { months } n(\%)\end{array}$ & $40(87)^{\mathrm{a}}$ & $8(57)$ & $6(67)^{b}$ & - \\
\hline
\end{tabular}

Pleocytosis: $>5$ mononuclear cells $/ \mathrm{mL}$ CSF

LNB Lyme neuroborreliosis, $n$ number of patients, $A b^{+}$antibody, $A l$ antibody index, CSF cerebrospinal fluid, $S$ serum, $L P$ lumbar puncture

*Significant difference compared to the non-LNB group (group 4). ${ }^{*} p<0.01$, ${ }^{* *} p<0.001$, ${ }^{* *} p<0.0001$

${ }^{a}$ Group 1: information was lacking in 3 patients, thus total $n=46$

${ }^{\mathrm{b}}$ Group 3: five patients did not receive any treatment, thus total $n=9$

parametrical Kruskal-Wallis test and when $p<0.05$ followed by Mann-Whitney $U$ test as a post hoc test. For children (age $<15$ years), a covariance analysis has been performed with pleocytosis as a covariate. Data are given as medians and interquartile (i.q. range). For categorical variables, the chi-square test was used. Correlations were determined by Spearman's rank order correlation. $p$ values below 0.05 were considered significant.

\section{Results}

\section{General description of the patients}

Table 1 presents the characteristics of the different study groups. There were significant differences in age with, older individuals in group 3 compared to group 2 which consisted mainly of children. Median duration of symptoms before LP was similar in groups 1 and 3 but several days shorter in group 2. A majority of patients in groups

Table 2 Characteristics of clinical parameters in group 2 (possible LNB pleocytosis)

\begin{tabular}{|c|c|c|c|c|c|c|c|c|}
\hline Pat. Nr. & Symptoms before LP & Head/neck & Fatigue & Fever & Vertigo & Radiculitis & Cranial nerve & Other symptoms \\
\hline & Weeks & Pain & & & & & Palsy & \\
\hline 1 & 0.7 & & & & & & $x$ & \\
\hline 2 & 0.3 & & & & & & $x$ & \\
\hline 3 & 1.6 & $x$ & & & & & $x$ & \\
\hline 4 & 0.4 & $x$ & $x$ & & & & & \\
\hline 5 & 1.0 & & & & & $x$ & & \\
\hline 6 & 0.6 & & & & & & $x$ & \\
\hline 7 & 0.4 & & & & & & $x$ & \\
\hline 8 & 0.1 & $x$ & $x$ & & & & $x$ & \\
\hline 9 & 0.4 & & & & & & $x$ & \\
\hline 10 & 0.3 & & $x$ & & & & $x$ & \\
\hline 11 & 3.0 & $x$ & $x$ & & & & & \\
\hline 12 & 0.7 & $x$ & $x$ & & $x$ & & & \\
\hline 13 & 1.0 & $x$ & $x$ & $x$ & & $x$ & & \\
\hline 14 & 0.3 & & & $x$ & & & $x$ & \\
\hline
\end{tabular}


Table 3 Characteristics of clinical parameters in group 3 (possible LNB Ab+)

\begin{tabular}{|c|c|c|c|c|c|c|c|c|}
\hline Pat. Nr. & Symptoms before LP & Head/neck & Fatigue & Fever & Vertigo & Radiculitis & Cranial nerve & Other symptoms \\
\hline & Weeks & Pain & & & & & Palsy & \\
\hline 1 & 72 & $x$ & $x$ & & & & & \\
\hline 2 & 3 & $x$ & & & & $x$ & & \\
\hline 3 & 156 & & & & & & & Unilateral vision loss \\
\hline 4 & 2 & $x$ & & & $x$ & & & \\
\hline 5 & 104 & & & & & & & Dysarthria, dysphagia \\
\hline 6 & 52 & & & & & & & Dysarthria, memory loss \\
\hline 7 & 7 & $x$ & & & & & & \\
\hline 8 & 1 & $x$ & & & $x$ & & & \\
\hline 9 & 2 & $x$ & $x$ & & & & & \\
\hline 10 & 0.7 & & & & & & & Unilateral vision loss \\
\hline 11 & 0.4 & $x$ & & & $x$ & & & Dysarthria, vision loss \\
\hline 12 & 0.1 & & & & $x$ & & & Decreased consciousness \\
\hline 13 & 2 & $x$ & $x$ & & & & & \\
\hline 14 & 1 & & $x$ & & & & & Concentration difficulties \\
\hline
\end{tabular}

LNB Lyme neuroborreliosis, Pat. Nr. patient number, LP lumbar puncture

1 and 2 had symptom duration after treatment below 3 months. Tables 2 and 3 present symptoms and symptom duration before LP for patients in groups 2 and 3, respectively. All patients in group 2 had symptoms highly suggestive of LNB such as head or neck pain (or both), radiculitis or cranial nerve palsy. In group 3, no patients had cranial nerve palsy and only one had radiculitis and six patients had symptoms not typical for LNB, such as vision loss and dysarthria, and their duration of symptoms before LP ranged from less than a week to several years.

\section{B cell-associated cytokines and chemokines}

CSF levels of APRIL and CXCL13 (Table 4 and Fig. 1) were significantly elevated in all LNB groups compared to the non-LNB group (group 4) while there were no differences in serum. A majority of patients in groups 1 and 2, but not in group 3, had CSF levels of CXCL13

Table 4 Cytokines/chemokines in serum and CSF in the four study groups

\begin{tabular}{|c|c|c|c|c|}
\hline & $\begin{array}{l}\text { Group } 1 \\
\text { Definite LNB } \\
n=49 \\
\text { Median (interquartile) }\end{array}$ & $\begin{array}{l}\text { Group } 2 \\
\text { Possible LNB pleocytosis } \\
n=14 \\
\text { Median (interquartile) }\end{array}$ & $\begin{array}{l}\text { Group } 3 \text { Possible LNB Ab+ } \\
\mathrm{n}=14 \\
\text { Median (interquartile) }\end{array}$ & $\begin{array}{l}\text { Group } 4 \\
\text { Non-LNB patients } \\
n=88 \\
\text { Median (interquartile) }\end{array}$ \\
\hline S-APRIL (ng/mL) & $3.1(0.8-5.7)$ & $1.4(0.3-1.8)$ & $2.0(0.5-4.4)$ & $3.9(0.0-5.8)$ \\
\hline S-BAFF (pg/mL) & 705 (471-857) & $586(531-873)$ & $597(496-763)$ & 730 (581-935) \\
\hline S-CXCL13 (pg/mL) & 67 (38-99) & $56(39-84)$ & $41(30-58)$ & $54(34-81)$ \\
\hline S-IL-17A (pg/mL) & $4.0(2.6-10)$ & $4.5(2.9-9.2)$ & $5.6(2.9-7.1)$ & $9.8(2.6-24)$ \\
\hline $\mathrm{S}-\mathrm{CXCL} 1(\mathrm{pg} / \mathrm{mL})$ & $741(549-861)^{* * *}$ & 695 (598-1055) & $599(439-750)^{* * *}$ & $1113(830-2425)$ \\
\hline S-CCL20 (pg(mL) & $6.1(3.7-9.3)^{* * *}$ & $6.8(5.3-13)^{* * *}$ & $5.2(3.1-9.8)$ & $0.2(0.2-8.2)$ \\
\hline CSF-APRIL (ng/mL) & $7.4(4.7-17)^{* * *}$ & $7.0(4.6-9.7)^{* * *}$ & $4.9(3.9-6.1)^{* * *}$ & $0.0(0.0-2.9)$ \\
\hline CSF-BAFF (pg/mL) & $113(58-191)^{* * *}$ & $125(81-203)^{* * *}$ & $0.0(0.0-76)$ & $0.0(0.0-25)$ \\
\hline CSF-CXCL13 (pg/mL) & $974(738-2394)^{* * *}$ & $379(57-770)^{* * *}$ & $3.4(0.0-8.8)^{* * *}$ & $0.0(0.0-0.0)$ \\
\hline CSF-IL-17A (pg/mL) & $0.6(0.0-0.6)^{* * *}$ & $0.0(0.0-0.2)$ & $0.0(0.0-0.1)$ & $0.0(0.0-0.0)$ \\
\hline CSF-CXCL1 (pg/mL) & $52(16-117)^{* * *}$ & $16(2.1-37)$ & $12(4.4-21)^{*}$ & $21(16-26)$ \\
\hline CSF-CCL20 (pg/mL) & $2.5(2.2-2.8)^{* * *}$ & $2.3(1.9-2.6)^{* * *}$ & $2.2(1.9-2.5)^{* * *}$ & $0.4(0.4-0.4)$ \\
\hline
\end{tabular}

Pleocytosis: $>5$ mononuclear cells/mL CSF 
B cell Cyto/chemokines
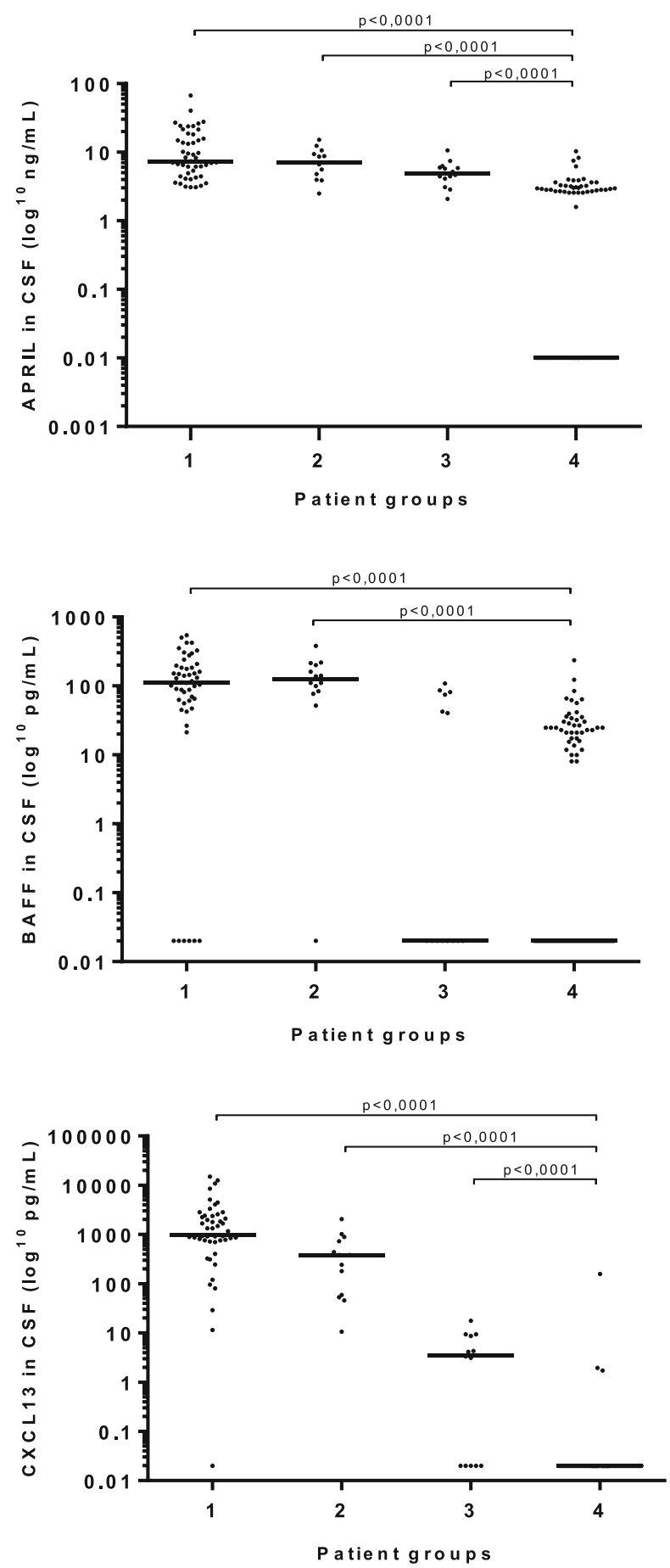

Th17 cyto/chemokines
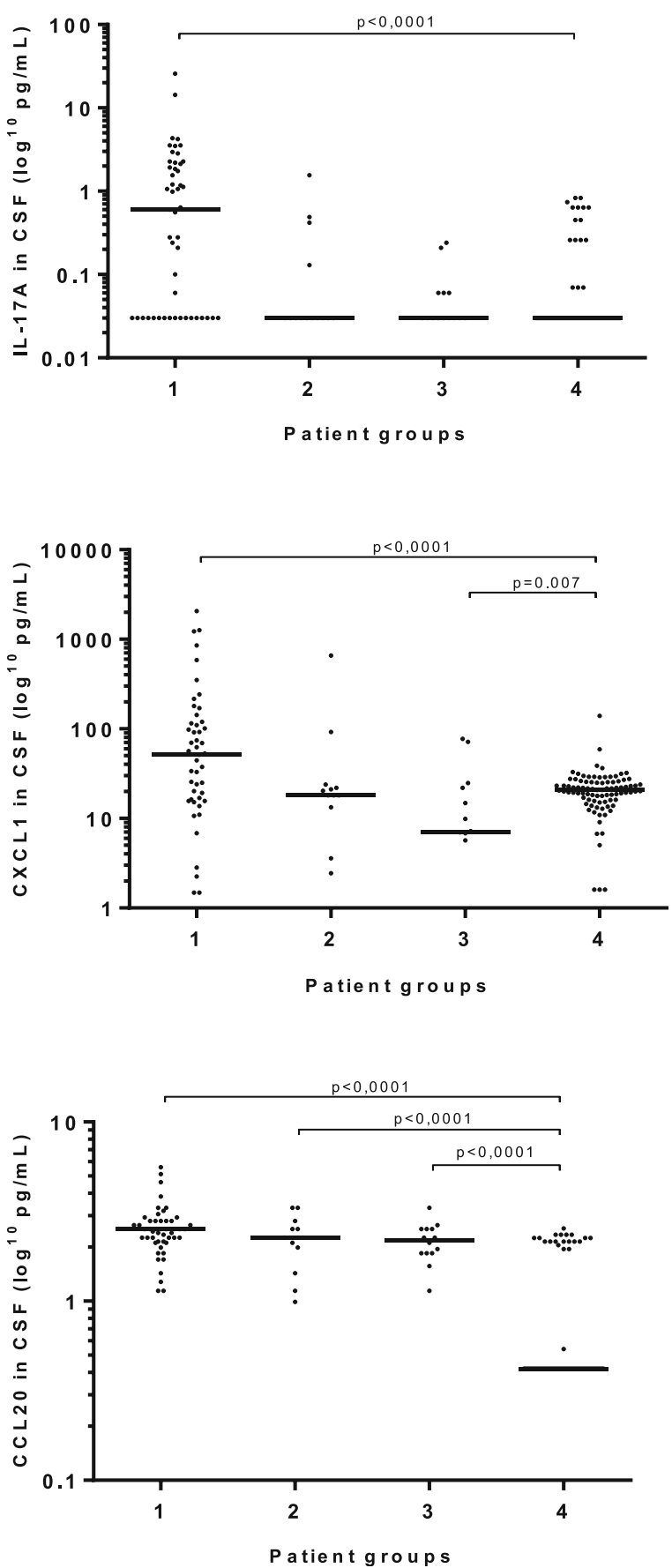

Fig. 1 B cell- and Th17-related cytokine/chemokine levels in cerebrospinal fluid (CSF).Group 1: definite Lyme neuroborreliosis (LNB), patients with Borrelia-specific antibodies in CSF and pleocytosis. Group 2: possible LNB pleocytosis, patients with CSF pleocytosis but no detectable Borrelia-specific antibodies in CSF. Group 3: possible LNB Ab', patients with Borrelia-specific antibodies in CSF but no pleocytosis. Group 4: non-LNB, patients without CSF pleocytosis and no detectable Borrelia-specific antibodies in serum or CSF. Bars represent the median cytokine/chemokine level in each group 
over the previously suggested cutoff levels of 142 and $250 \mathrm{pg} / \mathrm{mL}$ (Table 5). No correlations were seen between cytokine and chemokine levels in serum and CSF.

\section{Th17-associated cytokines and chemokines}

CSF levels of IL-17A, CXCL1 and CCL20 (Table 4 and Fig. 1), were all significantly elevated in group 1 compared to group 4. CCL20 was also significantly higher in groups 2 and 3 compared to group 4. In Table 4, serum levels of CXCL1 were significantly lower in groups 1 and 3 compared to group 4 whereas levels of CCL20 were significantly higher in groups 1 and 2 compared to group 4. CSF levels of IL-17A correlated with CXCL1 (rho $=0.72, p<0.0001$ ) in groups 1,2 and 3 . No correlations were seen between cytokine and chemokine levels in serum and CSF.

\section{Associations with demographic and clinical parameters}

There were no significant differences in cytokine/chemokine levels in serum or in CSF between men and women. Regarding differences in relation to age (data not shown), we found that children $<15$ years of age in groups 1,2 and $3(n=34)$ had significantly higher levels of BAFF (median $108 \mathrm{pg} / \mathrm{mL}$, i.q. range $60-165, p<0.001$ ) in serum and CXCL13 in serum and CSF $(77 \mathrm{pg} / \mathrm{mL}$, 47-109, $p=0.001$ and $920 \mathrm{pg} / \mathrm{mL}, 398-1706, p=0.03$, respectively) compared to adults. BAFF in serum also showed a strong negative correlation with age in groups 1 and 2 (rho $=-0.57, p<0.01)$. APRIL, BAFF and CXCL13 in CSF were all positively correlated with pleocytosis (rho $=0.51$, rho $=0.51$ and rho $=0.55$, respectively, all $p<0.001)$. When a covariate analysis was performed with pleocytosis as a covariate, BAFF in serum was still significantly higher in children $(p<0.0001)$, but CXCL13 in serum and CSF was not. Children in groups 1, 2 and 3 had significantly higher levels of CCL20 in serum and CSF $(8 \mathrm{pg} / \mathrm{mL}, 4-12$ and median $3 \mathrm{pg} / \mathrm{mL}, 2-3$, respectively, both $p=0.03)$. CCL20 was however not significantly higher when performing a covariate analysis with pleocytosis as a covariate. IL-17A levels in CSF correlated with pleocytosis (rho $=0.51, p<0.0001$ ).

Symptom duration before LP did not correlate with levels of cytokines/chemokines in serum or CSF in

Table 5 Number of patients with CXCL13 levels in CSF over 142 and $250 \mathrm{pg} / \mathrm{mL}$, respectively, in the four study groups

\begin{tabular}{lllll}
\hline & Group 1 & Group 2 & Group 3 & Group 4 \\
& Definite & Possible LNB & Possible & Non-LNB \\
& LNB & pleocytosis & LNB Ab & patients \\
& $n=49$ & $n=14$ & $n=14$ & $n=88$ \\
\hline$>142 \mathrm{pg} / \mathrm{mL} n(\%)$ & $43(88)$ & $10(71)$ & $0(0)$ & $1(1)$ \\
$>250 \mathrm{pg} / \mathrm{mL} n(\%)$ & $42(86)$ & $9(64)$ & $0(0)$ & $0(0)$ \\
\hline
\end{tabular}

Pleocytosis: $>5$ mononuclear cells $/ \mathrm{mL} \mathrm{CSF}$

CSF cerebrospinal fluid, LNB Lyme neuroborreliosis, $n$ number of patients, $\mathrm{Ab}^{+}$antibody groups 1, 2 and 3 together. However, within group 2, duration of symptoms before LP correlated negatively with BAFF and CXCL13 in serum (rho $=-0.57$ and -0.58 , respectively, both $p<0.01$ ). When stratifying patient in groups 1, 2 and 3 according to duration of symptoms before LP, those with a shorter duration ( $\leq 2$ weeks, $n=49$ ) had higher levels of BAFF in serum (median $764 \mathrm{ng} / \mathrm{mL}, 537-890, p=0.002)$ compared to patients with longer symptom duration $(n=28)(556 \mathrm{ng} / \mathrm{mL}, 438-668)$.

Regarding relation to disease course, patients in groups 1 and 2 were stratified according to time to recovery after treatment. Patients with shorter duration, group A ( $<3$ months, $n=54$ ) had lower levels of APRIL ( $p=0.003)$, BAFF $(p=0.04)$ and IL-17A $(p=0.02)$ in CSF compared to patients with longer time of recovery, group B ( $>3$ months, $n=6$ ), (Fig. 2).

\section{Discussion}

In this study, we showed that levels of several cytokines and chemokines related to Th17 and B cell immunity are raised in CSF from patients with LNB, strengthening the involvement of both Th17 and B cell immunity in LNB. Furthermore, we noted several relations to demographic and clinical parameters.

The lack of correlations between cytokine/chemokine levels in serum versus CSF indicates an intrathecal source of the cytokines and chemokines present in CSF, thus reflecting the pathological process in the CNS.

\section{B cell-related cytokines and chemokines}

CXCL13 was significantly elevated in CSF of all LNB groups, in particular the pleocytosis groups 1 and 2, as compared to the non-LNB group. CXCL13 has been suggested as a diagnostic marker for acute LNB, and a majority of patients in groups 1 and 2, those with most probable acute LNB, showed raised CSF levels above 142 and $250 \mathrm{pg} / \mathrm{mL}$, respectively, while no patients in group 3 had levels over $142 \mathrm{pg} / \mathrm{mL}$, supporting CXCL13 as a diagnostic tool and corroborating several studies $[4,6-8,21]$. Patients in groups 1 and 2 with CSF CXCL13 levels below the cutoff values did not, however, differ in symptoms, duration of symptoms before LP or time to recovery after treatment compared to patients with higher levels of CXCL13. Other diagnoses than LNB cannot be completely ruled out in patients with CSF-CXCL13 levels below $142 \mathrm{pg} / \mathrm{mL}$, especially in group 2 , since this group only displayed CSF pleocytosis. We suggest that the LNB diagnosis in group 3 is questionable since these patients displayed no CSF pleocytosis and had CSF-CXCL13 levels below the suggested cutoff $142 \mathrm{pg} / \mathrm{mL}$. Most of these patients reported symptoms less typical for LNB. Thus, the elevated AI could more likely reflect a previous infection, and other causes of their present symptoms are plausible. However, interestingly, slightly higher APRIL 


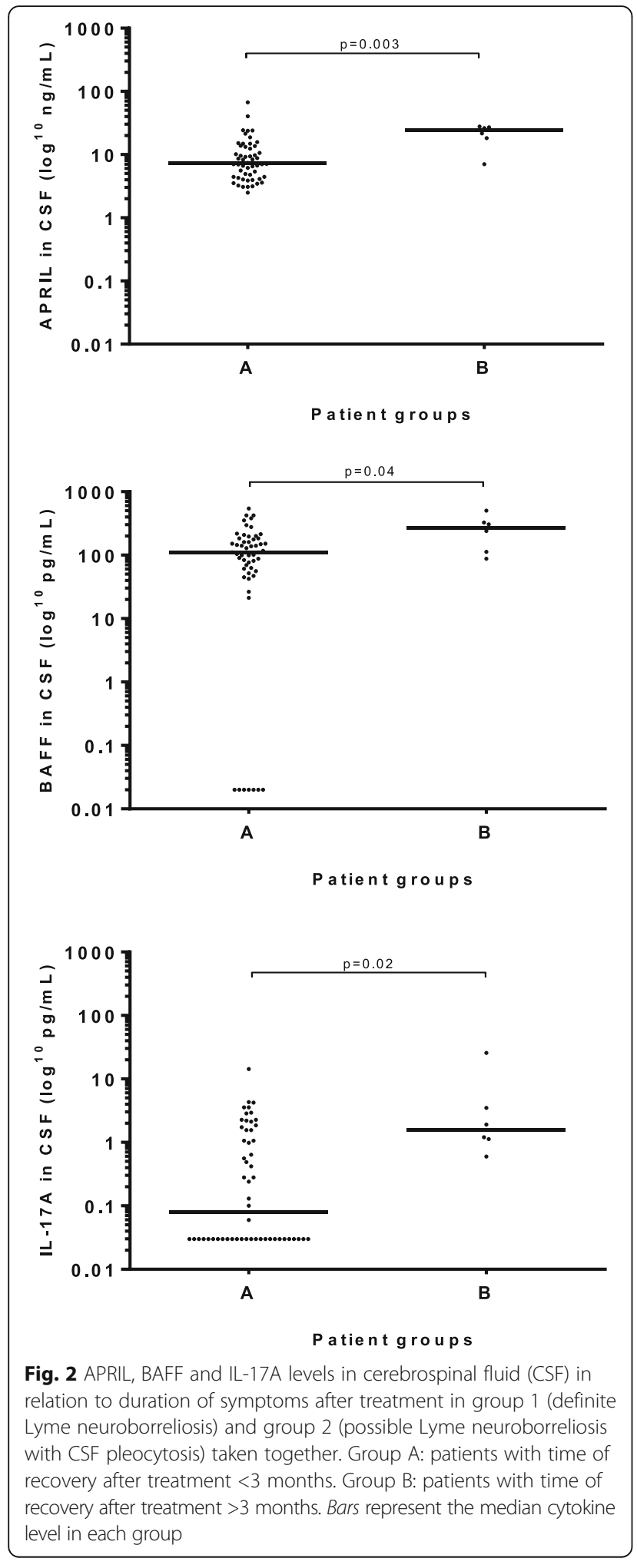

and CXCL13 CSF levels were found in this group compared with the non-LNB group, which may indicate a subtle ongoing B cell-related activity. On the other hand, CSF levels of CXCL1 were lower, strengthening group 3 as a different entity. Finally, regarding age, we corroborated previous findings [6] of increased levels of CXCL13 in children in both serum and CSF.

The involvement of B cell-related cytokines and chemokines in the pathogenesis of LNB is also supported by the raised CSF levels of both APRIL and BAFF in groups 1 and 2, the groups with most probable LNB. This is, to our knowledge, the first time elevated levels of APRIL has been reported in LNB patients, while BAFF has been studied previously [12]. The raised levels of APRIL and BAFF support the critical role of B cell activation and proliferation in LNB. However, moderately increased CSF levels of these cytokines were associated with shorter time to recovery (defined as $<3$ months), while higher levels were found in patients with longer time to recovery. Speculatively, moderate levels reflect an appropriate B cell response, while higher levels may reflect an over-shooting response mirroring or even contributing to more extensive CNS pathology. Increased levels of APRIL and BAFF have also been found in patients with multiple sclerosis [22] and systemic lupus erythematosus $[11,23]$, linked to antibody-mediated pathology and neuropsychiatric symptoms, respectively. Clearly, the role of APRIL and BAFF in LNB needs to be further elucidated, preferably in a prospective manner.

\section{Th17-related cytokines and chemokines}

We found elevated CSF levels of IL-17A in LNB patients, which corroborates previous studies [13-15]. We here extended the concept of Th17 immunity by showing elevated levels of CXCL1 and CCL20, both induced by Th17 and involved in recruitment of neutrophils and Th17 cells, respectively. CXCL1 in CSF, was significantly raised in group 1, while CCL20 in CSF was significantly raised in all definite and possible LNB (groups 1, 2 and 3). This is, to our knowledge, the first study that shows these Th17-related markers in patients with LNB. IL-17A, CXCL1 and CCL20 have however been reported present in other Lyme borreliosis manifestations, such as Lyme arthritis (IL-17), erythema migrans and acrodermatitis chronica atrophicans (CXCL1 and CCL20) [24, 25]. In experimental studies, CXCL1 was shown to be produced by human astrocytes and brain microvascular endothelial cells in response to B. burgdorferi [26]. Interestingly, patients who recovered within 3 months after treatment had lower levels of IL-17A in CSF. Thus, high levels of IL-17A in CSF may be a prognostic marker and speculatively, a Th17 response could be involved in the pathogenesis of a delayed therapeutic response. In line with this notion, patients with prolonged symptoms after treatment of neurosyphilis had higher levels of IL-17A in CSF [27]. Further on, Th17 immunity has been linked to many autoimmune conditions, like rheumatoid arthritis [28] and psoriasis [29]. In CNS, Th17-related immune responses play a role 
in experimental autoimmune encephalomyelitis (EAE), an animal model for multiple sclerosis [30]. CCL20 can bind to the choroid plexus and lead Th17-related cells into CNS [30]. Our findings add further aspects of the Th17related immune response in the pathogenesis of LNB and suggest that it may affect clinical course, although this needs to be confirmed.

There are some limitations of the current study. The retrospective design hampers clinical assessments. Another potential limitation is the lack of truly healthy controls, although the chosen group represents a clinically relevant reference group. Group 2, with mostly children, had CSF pleocytosis and characteristic symptoms of LNB, but other, foremost viral, infections cannot be completely ruled out, especially in cases with low CSF levels of CXCL13, since presence of neurotropic viruses was mostly not investigated. Regarding the EFNS guidelines, we note some limitations in the classification of possible LNB cases. According to the guidelines, patients corresponding to our groups 2 and 3 are classified as possible LNB, while we find important differences between the two groups in terms of clinical presentation and CSF findings, including cytokine and chemokine levels.

\section{Conclusions}

We here demonstrate additional support for Th17 involvement in the intrathecal immune response in LNB as well as indications that high levels of IL-17A in CSF in the acute phase of the disease may be associated with slower recovery, hence proposing that IL-17A should be further evaluated as a possible biomarker for prognosis. Besides CXCL13, the B cell-related cytokines APRIL and BAFF are elevated in CSF from patients with LNB, and the levels could be associated with time to recovery after treatment.

\section{Abbreviations}

Al: Antibody index; APRIL: A proliferation-inducing ligand; BAFF: B cell activating factor; CNS: Central nervous system; CSF: Cerebrospinal fluid; i.q.: Interquartile range; LNB: Lyme neuroborreliosis; LP: Lumbar puncture; Th cells: T helper cells

\section{Acknowledgements}

The authors would like to thank M.Sc. Malin Lager for the help with the laboratory analyses.

\section{Funding}

The study was supported financially by the Medical Research Council of Southeast Sweden (FORSS), Futurum - the Academy for Health and Care, the Division of Medical Services, Region Jönköping County, and the EU-Interreg project ScandTick Innovation.

\section{Availability of data and materials}

All materials used in this manuscript will be made available to researchers subject to confidentiality.

\section{Authors' contributions}

PF, JE and AJH planned the study. PG carried out the collection of background data from medical charts and carried out statistical analysis.
All authors helped with writing the manuscript. All authors have read and approved of the final manuscript.

\section{Competing interests}

The authors declare that they have no competing interests.

\section{Consent for publication}

Not applicable.

\section{Consent}

The study was approved by the Regional Ethical Review Board in Linköping, Sweden (2012/246-31). The patients had given a general consent to their samples being stored in a biobank and used for research purposes.

\section{Author details}

'Department of Infectious Diseases, Region Jönköping County, SE-551 85 Jönköping, Sweden. ${ }^{2}$ Department of Clinical and Experimental Medicine and Department of Infectious Diseases, Linköping University, Linköping, Sweden. ${ }^{3}$ Department of Clinical and Experimental Medicine and Department of Clinical Immunology and Transfusion Medicine, Linköping University, Linköping, Sweden. ${ }^{4}$ Clinical Microbiology, Division of Medical Services, Jönköping, Region Jönköping County, Sweden.

Received: 25 May 2016 Accepted: 4 January 2017

Published online: 01 February 2017

\section{References}

1. Berglund J, Eitrem R, Ornstein K, Lindberg A, Ringer A, Elmrud H, et al. An epidemiologic study of Lyme disease in southern Sweden. N Engl I Med. 1995;333(20):1319-27.

2. Cimmino MA. Relative frequency of Lyme borreliosis and of its clinical manifestations in Europe. European Community Concerted Action on Risk Assessment in Lyme Borreliosis. Infection. 1998;26(5):298-300.

3. Rupprecht TA, Plate A, Adam M, Wick M, Kastenbauer S, Schmidt C, et al. The chemokine CXCL13 is a key regulator of $B$ cell recruitment to the cerebrospinal fluid in acute Lyme neuroborreliosis. J Neuroinflammation. 2009;6:42.

4. Ljostad U, Mygland A. CSF B-lymphocyte chemoattractant (CXCL13) in the early diagnosis of acute Lyme neuroborreliosis. J Neurol. 2008;255(5):732-7.

5. Sillanpaa H, Skogman BH, Sarvas H, Seppala IJ, Lahdenne P. Cerebrospinal fluid chemokine CXCL13 in the diagnosis of neuroborreliosis in children. Scand I Infect Dis. 2013;45(7):526-30.

6. Tjernberg I, Henningsson AJ, Eliasson I, Forsberg P, Ernerudh J. Diagnostic performance of cerebrospinal fluid chemokine CXCL13 and antibodies to the C6-peptide in Lyme neuroborreliosis. The Journal of infection. 2011; 62(2):149-58.

7. Rupprecht TA, Pfister HW, Angele B, Kastenbauer S, Wilske B, Koedel U. The chemokine CXCL13 (BLC): a putative diagnostic marker for neuroborreliosis. Neurology. 2005;65(3):448-50.

8. Rupprecht TA, Lechner C, Tumani H, Fingerle V. CXCL13: a biomarker for acute Lyme neuroborreliosis: investigation of the predictive value in the clinical routine. Der Nervenarzt. 2014;85(4):459-64.

9. Mackay F, Schneider P, Rennert P, Browning J. BAFF AND APRIL: a tutorial on B cell survival. Annu Rev Immunol. 2003;21:231-64.

10. Sumita Y, Murakawa Y, Sugiura T, Wada Y, Nagai A, Yamaguchi S. Elevated BAFF levels in the cerebrospinal fluid of patients with neuro-Behcet's disease: BAFF is correlated with progressive dementia and psychosis. Scandinavian journal of immunology. 2012;75(6):633-40.

11. Hopia L, Thangarajh M, Khademi M, Laveskog A, Wallstrom E, Svenungsson E, et al. Cerebrospinal fluid levels of a proliferation-inducing ligand (APRIL) are increased in patients with neuropsychiatric systemic lupus erythematosus. Scandinavian journal of rheumatology. 2011;40(5):363-72.

12. Kowarik MC, Cepok S, Sellner J, Grummel V, Weber MS, Korn T, et al. CXCL13 is the major determinant for $B$ cell recruitment to the CSF during neuroinflammation. J Neuroinflammation. 2012:9:93.

13. Henningsson AJ, Tjernberg I, Malmvall BE, Forsberg P, Ernerudh J. Indications of Th1 and Th17 responses in cerebrospinal fluid from patients with Lyme neuroborreliosis: a large retrospective study. J Neuroinflammation. 2011;8:36.

14. Nordberg M, Forsberg P, Johansson A, Nyman D, Jansson C, Ernerudh J, et al. Cytotoxic mechanisms may play a role in the local immune response in 
the central nervous system in neuroborreliosis. Journal of neuroimmunology. 2011;232(1-2):186-93.

15. Liba Z, Kayserova J, Komarek V. Th1 and Th17 but no Th2-related cytokine spectrum in the cerebrospinal fluid of children with Borrelia-related facial nerve palsy. Fluids and barriers of the CNS. 2013;10(1):30.

16. Schwarzenberger P, La Russa V, Miller A, Ye P, Huang W, Zieske A, et al. IL-17 stimulates granulopoiesis in mice: use of an alternate, novel gene therapy-derived method for in vivo evaluation of cytokines. J Immunol. 1998;161(11):6383-9.

17. Park H, Li Z, Yang XO, Chang SH, Nurieva R, Wang YH, et al. A distinct lineage of CD4 $T$ cells regulates tissue inflammation by producing interleukin 17. Nature immunology. 2005;6(11):1133-41.

18. Mygland A, Ljostad U, Fingerle V, Rupprecht T, Schmutzhard E, Steiner I. EFNS guidelines on the diagnosis and management of European Lyme neuroborreliosis. Eur J Neurol. 2010;17(1):8-16. e1-4.

19. Link H, Tibbling G. Principles of albumin and IgG analyses in neurological disorders. III. Evaluation of IgG synthesis within the central nervous system in multiple sclerosis. Scandinavian journal of clinical and laboratory investigation. 1977;37(5):397-401.

20. BJ. P. Use and interpretation of tests in clinical immunology, 7th edn. Omaha: NE: Interstate Press; 1990

21. Wutte N, Berghold A, Loffler S, Zenz W, Daghofer E, Krainberger I, et al. CXCL13 chemokine in pediatric and adult neuroborreliosis. Acta neurologica Scandinavica. 2011;124(5):321-8.

22. Kothur K, Wienholt L, Tantsis EM, Earl J, Bandodkar S, Prelog K, et al. B cell, Th17, and neutrophil related cerebrospinal fluid cytokine/chemokines are elevated in MOG antibody associated demyelination. PloS one. 2016; 11(2):e0149411.

23. George-Chandy A, Trysberg E, Eriksson K. Raised intrathecal levels of APRIL and BAFF in patients with systemic lupus erythematosus: relationship to neuropsychiatric symptoms. Arthritis research \& therapy. 2008;10(4):R97.

24. Mullegger RR, Means TK, Shin JJ, Lee M, Jones KL, Glickstein LJ, et al. Chemokine signatures in the skin disorders of Lyme borreliosis in Europe: predominance of CXCL9 and CXCL10 in erythema migrans and acrodermatitis and CXCL13 in lymphocytoma. Infection and immunity. 2007;75(9):4621-8.

25. Codolo G, Amedei A, Steere AC, Papinutto E, Cappon A, Polenghi A, et al. Borrelia burgdorferi NapA-driven Th17 cell inflammation in lyme arthritis. Arthritis and rheumatism. 2008:58(11):3609-17.

26. Brissette CA, Kees ED, Burke MM, Gaultney RA, Floden AM, Watt JA. The multifaceted responses of primary human astrocytes and brain microvascular endothelial cells to the Lyme disease spirochete. Borrelia burgdorferi ASN neuro. 2013;5(3):221-9.

27. Wang C, Zhu L, Gao Z, Guan Z, Lu H, Shi M, et al. Increased interleukin-17 in peripheral blood and cerebrospinal fluid of neurosyphilis patients. PLoS neglected tropical diseases. 2014;8(7):e3004.

28. Schlegel PM, Steiert I, Kotter I, Muller CA. B cells contribute to heterogeneity of IL-17 producing cells in rheumatoid arthritis and healthy controls. PloS one. 2013;8(12):e82580.

29. Krueger JG, Fretzin S, Suarez-Farinas M, Haslett PA, Phipps KM, Cameron GS, et al. IL-17A is essential for cell activation and inflammatory gene circuits in subjects with psoriasis. The Journal of allergy and clinical immunology. 2012;130(1):145-54.e9.

30. Reboldi A, Coisne C, Baumjohann D, Benvenuto F, Bottinelli D, Lira S, et al. C-C chemokine receptor 6-regulated entry of TH-17 cells into the CNS through the choroid plexus is required for the initiation of EAE. Nature immunology. 2009;10(5):514-23.

\section{Submit your next manuscript to BioMed Central and we will help you at every step:}

- We accept pre-submission inquiries

- Our selector tool helps you to find the most relevant journal

- We provide round the clock customer support

- Convenient online submission

- Thorough peer review

- Inclusion in PubMed and all major indexing services

- Maximum visibility for your research

Submit your manuscript at www.biomedcentral.com/submit
Biomed Central 